\title{
How Well Do Wages Follow Productivity Growth?
}

\author{
Richard G. Anderson
}

$\mathrm{O}$ ver long periods of time, increases in "real" wages-that is, wages adjusted for changes in consumer prices-reflect increases in labor productivity. Economists now widely agree that labor productivity growth increased in the mid-1990s and remains at an elevated pace-at least relative to its anemic pace between 1973 and the mid-1990s. Numerous studies have traced the cause of the productivity acceleration to technological innovations in the production of semiconductors that sharply reduced the prices of such components and of the products that contain them (as well as expanding the capabilities of such products).

The impact of more rapid productivity growth on wages continues to be a topic of widespread economic research. Numerous news articles have discussed the apparent failure of wages to increase in line with productivity. Less appreciated, perhaps, is that the productivity acceleration has been accompanied by important changes in the way businesses compensate their employees. Of particular importance is the increased use of "variable pay," that is, compensation tied either to the performance of individual employees or to the business's overall performance, including end-ofyear bonuses, "cash awards," profit sharing, and stock options.

The chart compares labor productivity in the nonfarm business sector to two measures of real labor compensation: average hourly earnings for non-supervisory and production workers (AHE) in the upper panel, and total compensation per hour in the lower panel. AHE measures the typical, scheduled hourly wage plus legally required benefits but excludes variable pay-overtime, bonuses, shift premiums, and employer benefits. Total compensation, in contrast, includes variable pay. Increases in these compensation series track productivity quite closely through 1999. Beginning in 2000, however, AHE falls increasingly below productivity and increases little after 2003. Total compensation remains close until 2003, but does not follow 2003's uptick in productivity growth (behavior which remains a topic for future research).

Economists long have noted that focusing on AHE rather than total compensation yields an inaccurate picture of labor compensation due to the omission from AHE of employer-provided benefits. The trend toward increased use of variable pay provides an additional reason for focusing on broader compensation measures. But, why has more of labor compensation become variable pay? And why has this trend widened since 2000 ?
One reason, perhaps, is that the character of the productivity acceleration changed circa 2000. Prior to that date, studies have suggested that the more important effect was an increasing ratio of capital to labor (capital deepening) as businesses substituted relatively less expensive information technology and communication equipment for labor. Since 2000, some studies suggest that the more important factor has been a re-engineering of business practices, which has increased the "skill bias" in the labor market, that is, the premium paid for higher levels of technical, professional, and managerial education and experience. For employers, variable pay solves, in part, the problem of monitoring the performance of such workers: Unlike traditional factory and retail service workers, whose hours at work are relatively easily monitored, many skilled professionals work at varied locations and times of day. Finally, increasing reliance on variable pay also perhaps is a type of risksharing arrangement between businesses and workers. If the recent productivity trend slows, reducing or curtailing variable pay may be less offensive to professional workers than reductions in base salaries.

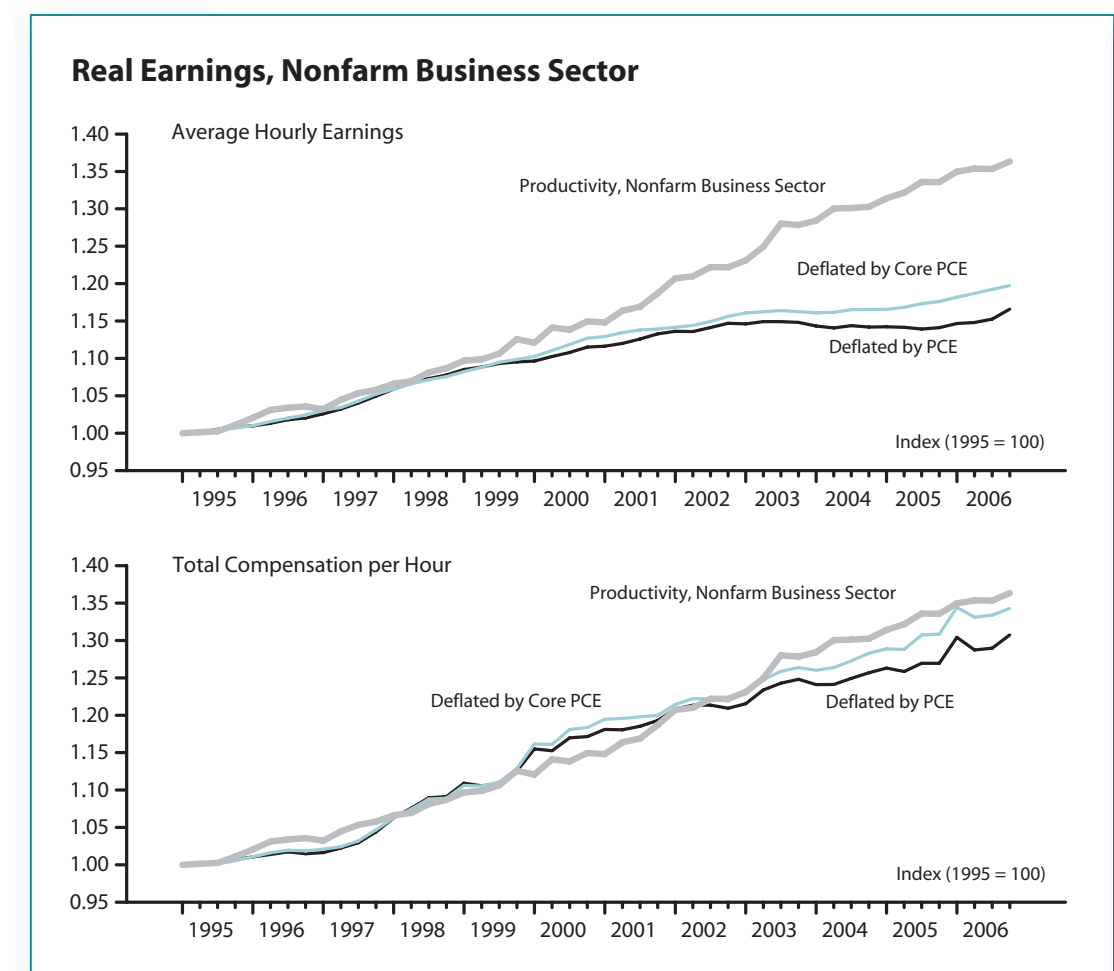

Views expressed do not necessarily reflect official positions of the Federal Reserve System. 